\title{
THE BIOCHEMISTRY AND ANTIBIOTIC SENSITIVITY OF THE KLEBSIELLAE
}

\author{
BY \\ SAMUEL S. EPSTEIN* \\ with the technical assistance of N. SPURLING \\ From the Department of Pathology of the Institute of Laryngology and Otology, London
}

(RECEIVED FOR PUBLICATION DECEMBER 12, 1957)

This paper presents a biochemical survey of a series of Klebsiellae. These findings are interpreted in the light of current taxonomical concepts. The antibiotic sensitivity of these organisms is also indicated.

\section{Material}

The material analysed here comprises a total of 82 strains. Thirty-two come from the National Collection of Type Cultures and are described in Table I. The remaining 50 strains were isolated at the Institute of Laryngology and Otology, mainly from infections of the upper respiratory tract. Data as to their source and serotype have already been presented (Epstein and Friedmann, 1958). In addition, the virulence of some of these strains for mice by oral and peritoneal routes of inoculation and the histopathology of pneumonic infections induced by them have been studied (Epstein and Payne. 1959 ; Epstein, 1959).

\section{Techniques}

Routine Biochemical Techniques.-All tests were performed at $37^{\circ} \mathrm{C}$. and media inoculated by Pasteur pipettes from overnight peptone water growths. Cyanide and Koser citrate media were inoculated by loops and straight wires respectively. Unless otherwise stated, all tests were read daily for seven days.

Carbohydrate Fermentation. - Sixteen carbohydrates listed in Table II were tested with Andrade's indicator in media consisting of $1 \stackrel{\circ}{\circ}$ carbohydrate $(\mathrm{w} / \mathrm{v})$ in peptone water.

Urease Test.-Christensen's (1946) weakly buffered urea agar medium was used.

Methyl-red and Voges-Proskauer Test.-The combined Ministry of Health (1939) oxoid media were used, and tests read at two days.

Koser Citrate Test.-Koser's (1923) medium was used, and positives confirmed by re-inoculation.

*Present address: Department of Morbid Anatomy. The Hospital for Sick Children, Great Ormond Street, London. W.C.1.
$\mathrm{H}_{2} \mathrm{~S}$ and Indole Production.--The combined SIM Difco (1953) medium was used and tested for indole at two and seven days.

Gelatin Liquefaction.---Liquefaction was observed in Difco gelatin agar stabs.

Nitrate Reduction.--Kauffmann's (1954) medium was used.

Cyanide Test.--The medium used was Taylor's (1956) modification of that described by Vagn Møller (1954b). This test is based on the finding by Braun

TABLE I

SOURCE AND SEROTYPE OF N.C.T.C. STRAINS ON KLEBSIELLAE

\begin{tabular}{|c|c|c|}
\hline Strain & Type & Source \\
\hline $\begin{array}{c}\text { K. pneumoniae (12) } \\
5054 \\
9494 \\
9502 \\
9503 \\
5055 \\
9128 \\
9129 \\
9130 \\
9131 \\
9132 \\
9133 \\
3279 \\
\end{array}$ & $\begin{array}{l}1 \\
1 \\
2 \\
2 \\
2 \\
8 \\
9 \\
10 \\
11 \\
12 \\
13 \\
\text { Untyped }\end{array}$ & $\begin{array}{l}\text { Pneumonia } \\
\text { Sputum } \\
\text { Urine } \\
\text { Unknown } \\
\quad, \\
\ddot{.} \\
., \\
\text { Pneumonia coyput }\end{array}$ \\
\hline $\begin{array}{c}\text { K.rhinoscleromatis }(6) \\
5046 \\
5047 \\
5048 \\
5049 \\
\\
1936 \\
7799\end{array}$ & $\begin{array}{ll}3 & \\
3 & \\
3 & \\
3 & \text { (acapsulate } \\
3 & \text { form 5048) } \\
3 & \end{array}$ & $\begin{array}{r}\text { Nose } \\
., \\
., \\
., \\
.,\end{array}$ \\
\hline $\begin{array}{c}\text { K. ozaenae }(7) \\
5050 \\
5051 \\
5053 \\
\\
5052 \\
8883 \\
9601 \\
8895\end{array}$ & $\begin{array}{l}4 \\
5 \\
5 \text { (acapsulate } \\
6 \text { form 5051) } \\
\text { Untyped } \\
\quad, . \\
.,\end{array}$ & 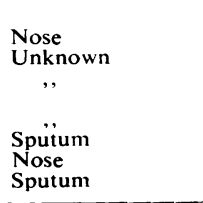 \\
\hline $\begin{array}{c}\text { K. “aerogenes" (7) } \\
9527 \\
8844 \\
8167 \\
8824 \\
8851 \\
8801 \\
8808\end{array}$ & $\begin{array}{l}\text { I } \\
\text { II } \\
\text { II } \\
\text { II } \\
\text { II } \\
\text { Untyped } \\
\quad,,\end{array}$ & $\begin{array}{l}\text { Water } \\
\text { Ice cream } \\
\text { Water } \\
\quad, \text {, } \\
\text { Sputum } \\
\text { Water }\end{array}$ \\
\hline
\end{tabular}


(1938) that the inhibitory effect of potassium cyanide on Klebsiellae is less than on Escherichiae.

Base.-The composition is as follows:

\begin{tabular}{lccccccc}
\multicolumn{2}{l}{ Evans' peptone } & $\ldots$ & $\ldots$ & $\ldots$ & $\ldots$ & $\ldots$ & $3 \mathrm{~g}$. \\
$\mathrm{NaCl}$ & $\ldots$ & $\ldots$ & $\ldots$ & $\ldots$ & $\ldots$ & $\ldots$ & $5 \mathrm{~g}$. \\
$\mathrm{KH}_{2} \mathrm{PO}_{4}$ & $\ldots$ & $\ldots$ & $\ldots$ & $\ldots$ & $\ldots$ & $\ldots$ & $0.225 \mathrm{~g}$. \\
$\mathrm{Na}_{2} \mathrm{HPO}_{4}$ & $\mathrm{H}_{2} \mathrm{O}$ & $\ldots$ & $\ldots$ & $\ldots$ & $\ldots$ & $\ldots$ & $5.6 \mathrm{~g}$. \\
Aq. dist. & $\ldots$ & $\ldots$ & $\ldots$ & $\ldots$ & $\ldots$ & $\ldots$ & $100 \mathrm{ml}$.
\end{tabular}

The base is adjusted to $p \mathrm{H} 7.6$ and then autoclaved in flasks. To $100 \mathrm{ml}$. of base, $1.5 \mathrm{ml}$. of a freshly prepared $0.5 \%$ potassium cyanide solution in sterile distilled water is added, giving a concentration of $1 / 13,300$. The medium is distributed in $1 \mathrm{ml}$. amounts in sterile bijou bottles and at $4^{\circ} \mathrm{C}$. is stable for one month. Readings are made at 24 and 48 hours. False positives may be obtained unless the caps of bottles are screwed tightly to achieve partial anaerobiosis.

Gluconate Test.-The medium is a modification by Shaw and Clarke (1955) of that originally described by Haynes (1951) for the identification of Pseudomonads. The test is based on the ability of some organisms to metabolize glucose by direct oxidation instead of by the usual oxidative phosphorylation. Gluconate is oxidized to a reducing compound, presumed to be potassium-2-ketogluconate. The medium is tubed in $3 \mathrm{ml}$. amounts and tested at two days with Benedict's qualitative reagent.

Malonate and Phenylpyruvic Acid Tests.-Shaw and Clarke (1955) combined Leifson's (1933) sodium malonate and Henriksen's (1950) phenylalanine oxidase test in a single medium by adding phenylalanine to Leifson's medium and supplementing with yeastrel. Both tests were read at 24 hours.

Amino-acid Decarboxylases. - The technique described here is based on Shaw and Clarke's (1955) method. It was, however, found impossible to obtain homogeneous suspensions from some mucoid strains of Klebsiellae by washing off agar slopes, and for this reason suspensions were harvested instead from fluid media.

Reagents.-All seven L. amino-acids listed in Table III were tested at $p \mathrm{H} 5.0$ and $0.03 \mathrm{M}$, except glutamic acid, in which case the concentration was reduced to $0.01 \mathrm{M}$ because of its strong buffer action at a low $p \mathrm{H}$. A $0.0125 \mathrm{M}$ phthalate buffer at $p \mathrm{H} 5.0$ was used. The indicator was $0.04 \%$ bromcresol purple in distilled water at $p \mathrm{H}$ 5.0. All reagents were stored at $4^{\circ} \mathrm{C}$., with a drop of toluene added to prevent the growth of moulds.

Tubes.-Non-sterile 3 in. by $\frac{1}{2}$ in. tubes were used. Scrupulous chemical cleanliness was, however, essential, as traces of detergent produced false positive results.

Suspensions.-Strains under test were grown in peptone water at $37^{\circ} \mathrm{C}$. for four hours.

As maximal decarboxylase activity develops at an acid $p \mathrm{H}$, they were then subcultured to glucose broth and incubated for 16 hours at $37^{\circ} \mathrm{C}$. The broths were then centrifuged at 3,000 r.p.m. for five minutes and supernatants discarded. The deposits were suspended in saline, centrifuged, and the supernatants again discarded. Approximately $0.5 \mathrm{ml}$. of distilled water at $p \mathrm{H} 5.0$ was added, and the deposits resuspended to give suspensions of concentrations greater than $10^{9}$ organisms $/ \mathrm{ml}$. (opacity tubes). As shown by Vagn Møller (1954a), the permeability of the bacterial cell membrane to amino-acids is increased by treatment with various lipoid solvents. Consequently $0.05 \mathrm{ml}$. of toluene was added to the suspensions, which were then incubated at $37^{\circ} \mathrm{C}$. for 10 minutes.

Test.-Apart from controls, seven tubes corresponding to the substrates were required for each strain under test. To each tube the following were added with a 50 dropper: (1) 2 drops of suspension, (2) 2 drops of substrate, (3) 2 drops of buffer, (4) 1 drop of indicator. The mixtures were then incubated at $37^{\circ} \mathrm{C}$. for four hours.

Controls.-Two controls were employed with each set of tests, namely, (1) buffer, suspension, and indicator (no substrate) ; (2) buffer, heat-killed suspension, indicator, and substrate.

Readings.-The $p \mathbf{H}$ change was read at half, one, and four hours. Vagn Møller (1955) indicated that under these conditions of test $p \mathrm{H}$ change in an arginine substrate can be affected by arginine dihydrolase besides decarboxylase. For this reason the specificity of $p \mathrm{H}$ changes in arginine tubes was checked by Nesslerization, as ammonia formation precludes significant decarboxylase activity. Random tubes producing an indicator change in the lysine substrate were checked chromatographically. Butanol with $2 \mathrm{~N} . \mathrm{NH}_{4} \mathrm{OH}$ was the solvent and an ascending technique with Whatman No. 1 paper was used. Spots were identified with $0.1 \%$ ninhydrin in chloroform.

Amino-acid Oxidases.-The technique is similar to that described for decarboxylase determinations. These tests, however, were carried out at a more alkaline $p \mathrm{H}$, and the production of a keto-acid determined colorimetrically with ferric chloride rather than by indicator change.

Reagents. $-\mathrm{L}$. amino-acids at $p \mathrm{H} 6.8$ of the same molarity as previously were used. The buffer was $0.025 \mathrm{M}$ phosphate at $p \mathrm{H} 6.8$, and the keto-acid reagent $0.5 \mathrm{M}$ ferric chloride.

Suspensions. - These were similarly prepared, except that strains were grown in nutrient rather than glucose broth and subsequently suspended in distilled water at $p \mathrm{H} 6.8$.

Tests.-The mixtures were incubated at $37^{\circ} \mathrm{C}$. and samples tested at one and 24 hours with a drop of ferric chloride.

Antibiotic Sensitivity.-Sensitivity to the eight antibiotics in Table II was tested by Kohn's (1953a) simple diffusion technique. Sensitivity limits of organisms inhibited by erythromycin, oleandomycin, and novobiocin were estimated by the usual tube technique. Titrations extended over a range of 40 to 0.15 units. 


\section{Results}

Table II summarizes in percentage form the results of the above tests. For purposes of convenience, the 82 analysed strains are arranged in the seven groups indicated. Whereas all untyped and acapsulate strains from the Institute of Laryngology and Otology and the untyped N.C.T.C. strain 3279 are relegated to their appropriate group, the two acapsulate N.C.T.C. strains are classified with their corresponding capsular types. The captions rhinoscleroma, ozaenae, and aerogenes are used without prejudice at this stage.

The decarboxylase activity of all strains is analysed in Table III. Under the conditions of

TABLE II

SUMMARY OF BIOCHEMISTRY AND ANTIBIOTIC SENSITIVITY OF 82 STRAINS OF KLEBSIELLAE*

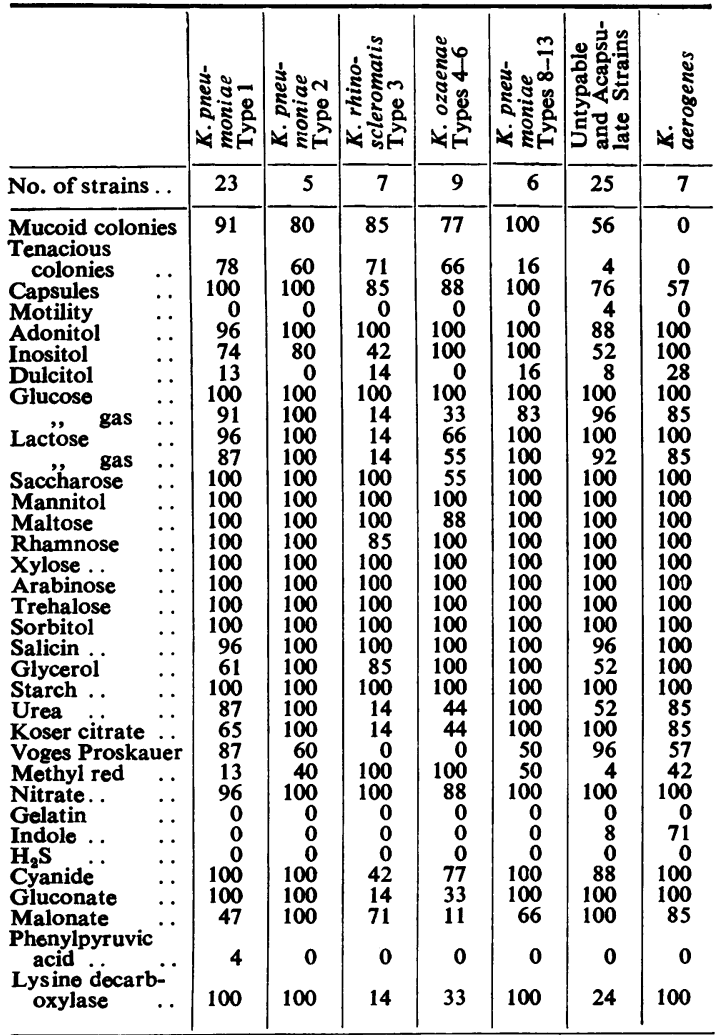

Percentage of strains sensitive to :

\begin{tabular}{|c|c|c|c|c|c|c|c|}
\hline $\begin{array}{l}\text { Penicillin } . . \\
\text { Tetracycline . } \\
\text { Streptomycin .. } \\
\text { Chloramphenicol } \\
\text { Polymyxin . } \\
\text { Erythromycin . } \\
\text { Oleandomycin } \\
\text { Novobiocin .. }\end{array}$ & $\begin{array}{r}0 \\
100 \\
100 \\
100 \\
78 \\
0 \\
0 \\
0\end{array}$ & $\begin{array}{r}0 \\
100 \\
100 \\
100 \\
60 \\
0 \\
0 \\
0\end{array}$ & $\begin{array}{r}0 \\
100 \\
100 \\
100 \\
71 \\
85 \\
85 \\
85\end{array}$ & $\begin{array}{r}0 \\
100 \\
100 \\
100 \\
88 \\
0 \\
0 \\
0\end{array}$ & $\begin{array}{r}0 \\
100 \\
100 \\
100 \\
66 \\
0 \\
0 \\
0\end{array}$ & $\begin{array}{r}0 \\
100 \\
96 \\
100 \\
60 \\
0 \\
0 \\
0\end{array}$ & $\begin{array}{r}10 \\
10 \\
10 \\
7\end{array}$ \\
\hline
\end{tabular}

*Expressed as percentages of strains giving positive reactions. test, a shift of $p \mathrm{H}$ after half an hour is indicative of feeble enzyme activity. Feeble arginine decarboxylase activity was demonstrated in 40 strains. The specificity of these delayed $p \mathrm{H}$ changes was confirmed by Nesslerization, with negative results in all cases. As is apparent, the majority of typed strains, including aerogenes, but with the notable exception of all but one type 3 and more than half type 4-6 strains, possessed strong lysine in decarboxylase activity. These results are also listed in Table II for purposes of correlation with the other tests. The reaction products of randomly selected strains, exhibiting strong lysine decarboxylase activity, were determined chromatographically and spots with $\mathbf{R}_{\mathbf{f}}$ values equivalent to cadaverine (decarboxylated lysine) were obtained (Fig. 1). By use of the combined malonate and phenylpyruvic acid medium, phenylalanine oxidase activity was detected in only one type 1 strain. Micro tests, however, proved uniformly negative.

Antibiotic sensitivity results determined by a diffusion technique are listed in Table II. Titrations demonstrated that all anaerogenic rhino-

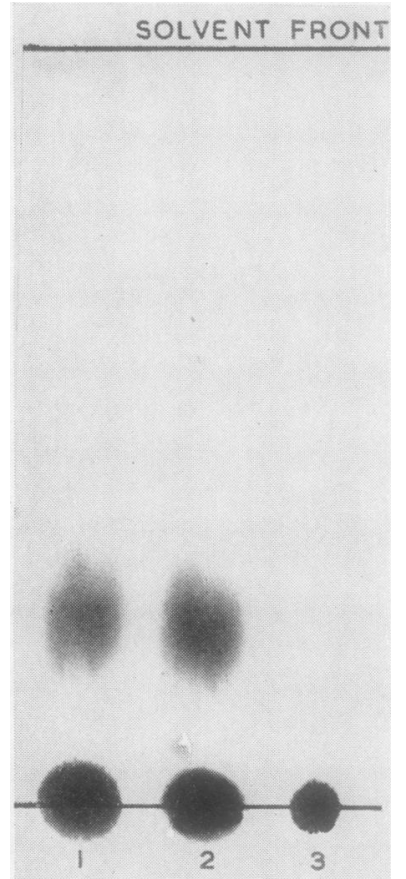

FIG. 1.-Chromatographic identification of cadaverine produced by enzymatic decarboxylation of lysine. (1) Test : Klebsiella suspension, buffer, indicator, and lysine. (2) Control: Buffer, indicator, and cadaverine. (3) Control: Heated Klebsiella suspension, buffer, indicator, and lysine. (Solvent-butanol with $2 \mathrm{~N}$. $\mathrm{NH}_{4} \mathrm{OH}$ : Whatman No. 1 paper; time of running-16 hr.) 
TABLE III

AMINO-ACID DECARBOXYLASE ACTIVITY IN KLEBSIELLAE

\begin{tabular}{|c|c|c|c|c|c|c|c|c|c|c|c|c|c|c|c|c|c|c|c|c|c|}
\hline & & & & & \multirow{2}{*}{ No. } & \multicolumn{4}{|c|}{ Lysine } & \multicolumn{2}{|c|}{ Arginine } & \multicolumn{2}{|c|}{ Ornithine } & \multicolumn{2}{|c|}{ Histidine } & \multicolumn{2}{|c|}{ Tyrosine } & \multicolumn{2}{|c|}{$\underset{\text { Acid }}{\text { Glutamic }}$} & \multicolumn{2}{|c|}{$\begin{array}{l}\text { Phenyl- } \\
\text { alanine }\end{array}$} \\
\hline & & & & & & - & \pm & + & ++ & - & \pm & - & \pm & - & \pm & - & \pm & - & \pm & - & \pm \\
\hline \multirow{2}{*}{\multicolumn{2}{|c|}{$\begin{array}{cc}\text { Type } 1 & \ldots \\
\text {, } 2 & \ldots \\
\text {," } 3 & \ldots \\
\text { Types } 4-6 & \ldots \\
\text { ", 8-13 } & \ldots \\
\text { Untypable and aca } \\
\text { "Aerogenes ", }\end{array}$}} & $\begin{array}{l}\ldots \\
\ldots \\
\ldots \\
\ldots \\
\ldots \\
\text { psulate } \\
\ldots\end{array}$ & $\begin{array}{l}\ldots \\
\ldots \\
\ldots \\
\ldots \\
\ldots \\
\ldots\end{array}$ & $\begin{array}{l}\cdots \\
\cdots \\
\cdots \\
\cdots \\
\cdots\end{array}$ & $\begin{array}{r}23 \\
5 \\
7 \\
9 \\
6 \\
25 \\
7\end{array}$ & $\begin{array}{l}5 \\
4 \\
3\end{array}$ & $\begin{array}{l}1 \\
2 \\
9\end{array}$ & & $\begin{array}{r}23 \\
5 \\
1 \\
3 \\
6 \\
13 \\
7\end{array}$ & $\begin{array}{r}10 \\
1 \\
7 \\
9 \\
2 \\
7 \\
6\end{array}$ & $\begin{array}{r}13 \\
4 \\
\\
4 \\
18 \\
1\end{array}$ & $\begin{array}{r}18 \\
4 \\
7 \\
9 \\
6 \\
10 \\
7\end{array}$ & $\begin{array}{l}5 \\
1\end{array}$ & $\begin{array}{r}23 \\
5 \\
7 \\
9 \\
6 \\
25 \\
7\end{array}$ & & $\begin{array}{r}23 \\
5 \\
7 \\
9 \\
6 \\
25 \\
7\end{array}$ & & $\begin{array}{r}23 \\
4 \\
7 \\
9 \\
6 \\
10 \\
7\end{array}$ & 15 & $\begin{array}{r}23 \\
5 \\
7 \\
9 \\
6 \\
20 \\
7\end{array}$ & 5 \\
\hline & & & Total & . & 82 & 12 & 12 & & 58 & 42 & 40 & 61 & 21 & 82 & & 82 & & 66 & 16 & 77 & 5 \\
\hline
\end{tabular}

$+t=p \mathrm{H}$ change less than $\frac{1}{2}$ hour. $t=p \mathrm{H}$ change $\frac{1}{2}-1$ hour. $\pm=p \mathrm{H}$ change $1-4$ hours. $-=$ No change at 4 hours.

scleroma strains were sensitive to erythromycin, oleandomycin, and novobiocin over a range of 0.3 to $1.25 \mathrm{ml}$. with the exceptions of strain 1936 sensitive to $10 \mathrm{u} . / \mathrm{ml}$. oleandomycin and $5 \mathrm{u} . / \mathrm{ml}$. novobiocin, and strain 7799 sensitive to $5 \mathrm{u} . / \mathrm{ml}$. oleandomycin.

\section{Discussion}

Bergey's “Manual” (Breed, Murray, and Hitchens, 1948) divides the tribe Eschericheae into three genera, namely, Escherichia, Aerobacter, and Klebsiella. Edwards (1929) challenged the identity of Aerobacter, of which aerogenes was the type species, and concluded that there was no justification for its extrageneric differentiation from Klebsiellae. Kauffmann (1949), among other workers, proposed that aerogenes strains be classified in the Klebsiella genus. Nearly all strains originally submitted to the N.C.T.C. as aerogenes have recently been reclassified as $K$. pneumoniae (Medical Research Council, 1958). Cowan (1956) in a recent survey of problems of nomenclature suggested that aerogenes be accepted as a Klebsiella subgroup for the convenience of water bacteriologists, who would be loath to report on the isolation of $K$. pneumoniae from a potable water. By implication, however, he accepted that source of origin is not a valid taxonomic criterion and that the designation aerogenes has thus no true status. Furthermore, Clarke and Tracey (1956) recently ascertained that high yields of chitinase and cellulase, constitutive enzymes supposedly characterizing many species of soil and water bacteria including aerogenes, can also be isolated from Klebsiellae of human origin. Cowan (1954) also indicated the undesirability of the epithet pneumoniae for the Klebsiella type species. He suggested instead the name friedlaenderi, which does not suggest an obligate relationship with respiratory infections.

The Klebsiella genus was originally intended to include a heterogeneous group of non-motile capsulated organisms, with an indole, methyl red, Voges-Proskauer and citrate formula $(1 \mathrm{MViC})$ --++ Both intrageneric and extrageneric biochemical and serological overlap have complicated the issue. Whether or not a particular organism be relegated to this genus may depend on the relative emphasis placed on any particular criterion. Serologically, for instance, an organism may belong to the Escherichiae and biochemically to the Klebsiellae-or vice versa. In such cases a decision as to which property represents the aberrance may prove impossible. In an attempt to discourage undue reliance on any given criterion as a basis for classification, Clarke (1955) suggested that the distribution of biochemical characters be best described on a statistical rather than on an "all or none" basis. Sneath (1957) has recently lent practical emphasis to this concept by demonstrating the application of mathematical computers to such taxonomical problems.

Kauffmann $(1949,1954)$ accepted only two biochemical species, $K$. pneumoniae and rhinoscleroma. Edwards and Fife (1955) further stressed that types 4-6, sometimes associated with ozaena, represent a diffuse biochemical transition between these two species and not a discrete entity. Henriksen (1952) proposed that ozaenae and aerogenes species be also recognized. Other workers, including Ørskov (1957), recommended the acceptance of further biochemical subtypes. The perpetuation of the name "rhinoscleroma" for type 3 organisms is based on tenuous evidence. Occasionally type 3 strains can be isolated from extranasal sites. Moreover, an aetiological relationship between the organism and disease is not proven. It is felt consequently that such strains should preferably be described numerically by their capsular antigen. The status of motile strains is still sub judice. Those liquefying gelatin are best classified as Cloaca cloacae, in accordance with Kauffmann (1954), or, as Cowan (1956) suggests, Klebsiella cloacae. Edwards and Fife 
(1955) recommend the designation Aerobacter cloacae. Possibly non-liquefying strains represent biochemical variants, and, as Cowan (1956) further proposes, should also be included. The Institute of Laryngology and Otology strain 3502 of the present series was such a motile nonliquefying strain.

Typical pneumoniae strains are usually aerogenic, lactose, citrate, Voges-Proskauer, malonate, cyanide, gluconate, and lysine positive. Type 3 strains possess the reverse properties. Strains belonging to types 4-6 are sometimes aerogenic, citrate, cyanide, and lysine positive, and usually malonate and Voges-Proskauer negative. However, as indicated in Table II, biochemical aberrance is common in pneumoniae, especially in type 1 strains. It is less frequent in type 3 strains. One of the seven type 3 strains of the present series was aerogenic, lactose, and lysine positive. In fact, although serologically this strain (No. 615) belonged to type 3 , it exhibited the biochemical features of a typical pneumoniae. Henriksen (1954) also described such strains and discussed this problem of mutually exclusive criteria.

Of the 82 strains of Klebsiellae studied in the present series, 15 were anaerogenic, of which six belonged to type 3 and five to types 4-6. As indicated previously, gas production in type 3 strains can be correlated with other biochemical features. The majority of anaerogenic strains were Voges-Proskauer negative and failed to ferment lactose. There were no other lactosenegative strains. Pickett and Cabelli (1953) stressed the low degree of biochemical reactivity of their lactose-negative strains, the majority of which, unlike those studied here, also failed to ferment adonitol and inositol. The fermentations of the former and to a lesser extent of the latter are fairly reliable differential tests between Klebsiellae and Escherichiae. Occasional strains failing to ferment these carbohydrates appeared otherwise biochemically typical. Dulcitol fermentation appears rare in Klebsiellae. Kauffmann (1954) pointed out that type 10 is characteristically dulcitol positive and this was in fact confirmed by the behaviour of the single type 10 strain studied. In addition, the aerogenic type 3 strain was also positive. In the few remaining dulcitolpositive strains, no other constant or significant biochemical deviation was observed.

Kligler (1914), on the basis of a biochemical comparison between cloacae and aerogenes strains, maintained that gelatin liquefaction was inversely related to gas production from glycerol. Edwards and Fife (1955) have shown, however, that
Klebsiellae occasionally fail to produce gas from glycerol, as did eight strains in the present series. No gelatin-liquefying strains were isolated, although, as Lautrop (1956) pointed out, extended incubation or the use of the Kohn (1953b) technique may possibly unmask some liquefiers. Delayed hydrolysis of urea and utilization of citrate is characteristic of most pneumoniae strains. Type 3 strains, with the exception of the aerogenic variant, were uniformly negative. Type 4-6 strains again behaved in an intermediate fashion, and those utilizing citrate did so only after four days. Occasional pneumoniae strains were also citrate and urease negative. Kauffmann (1954) pointed out that citrate-positive Escherichiae are very rare, and that no urease-positive strains have ever been described. Cowan (1957) has, however, encountered urease positive Escherichiae. Contrary to the findings of Kauffmann (1954), the single strains of Klebsiellae types 9 and 10 studied in this series were citrate positive. The methyl red and Voges-Proskauer are by no means clear-cut tests. Results depend on temperature, duration of incubation, method of testing, and, as indicated by Jennens (1954), the nature of the substrate. Of the 89 strains of Klebsiella pneumoniae recently studied by Vagn Møller (1954c), 89\% were VogesProskauer positive at one day, but only $45 \%$ at four days. Variables such as these make it difficult to compare results under different conditions of test. However, in this study all type 3-6 strains were methyl red positive. Contrary to Leifson (1933), who found an absolute correlation between Voges-Proskauer production and malonate utilization, the strains studied here exhibited an approximate correlation only. Indole production, while rare in Klebsiellae, is usual in Escherichiae. Of 626 Klebsiella strains studied by Edwards and Fife (1955), only 26 were indole positive. "Aerogenes" type II strains are rare, but indole positive by definition. Apart from these, only two other strains from the Institute of Laryngology and Otology produced indole, namely, the motile strain 3502 referred to previously and also the acapsulate strain 3872 which was otherwise biochemically typical. Reduction of nitrates is a non-specific test and only one negative was encountered. It is generally accepted that failure to produce $\mathrm{H}_{2} \mathrm{~S}$ is a reliable exclusion test for Klebsiellae; all strains in this series were negative. Clarke (1953) has, however, demonstrated that by the use of N.C.T.C. methods of testing the reverse findings may be elicited.

Resistance to cyanide inhibition and the ability to form reducing end-products from gluconate 
are differential tests of the utmost value. With the exception of some type 3-6 strains, the great majority of Klebsiellae tested were positive. There was, moreover, almost an absolute correlation between these tests.

The classical manometric studies of Gale (1946) on the decarboxylases demonstrated the varied and distinctive pattern of the enzymatic repertoire of different groups of bacteria. Subsequent workers, notably Woiwod (1949), Vagn Møller (1954c, 1955), and Shaw and Clarke (1955), introduced a variety of simplified techniques and stressed their practical application. Vagn Møller (1954c) examined a total of 671 Enterobacteriaceae and found that no strain, apart from $K$. pneumoniae, possessed powerful lysine and no other decarboxylase. The specificity of this test, as confirmed by the results in the present series, is thus high. Anaerogenic type 3 strains are consistently negative and pneumoniae strains almost invariably positive. Type 4-6 strains behaved in a variable manner, as did untyped and acapsulate strains. Unlike Shaw and Clarke (1955), who were able to demonstrate weak phenylalanine oxidase activity in some Klebsiellae, this was detected in one strain only by the combined medium and not by the micro test.

All strains examined were penicillin resistant, tetracycline, chloramphenicol, and streptomycin sensitive, with the exception of one, resistant to the last antibiotic. There is ample evidence, as reported by Finland, Murray, Harris, Kilham, and Meads (1946) and Ørskov (1952), that resistance to streptomycin often develops during treatment. Approximately two-thirds of strains were polymyxin sensitive. There appear to be scanty data on the sensitivity of Klebsiellae to some of the more recently introduced antibiotics. Coppo (1957) found that the minimum inhibitory concentration of novobiocin against 10 strains of "aerogenes" ranged from 250 to $500 \mathrm{u} . / \mathrm{ml}$. Erasmus (1956) reported on seven erythromycin-resistant untyped Klebsiellae. Apart from the aerogenic variant, all other type 3 strains exhibited suprising sensitivity to erythromycin, oleandomycin, and novobiocin. It is interesting that this previously unrecorded sensitivity pattern is restricted to the anaerogenic type 3 strains, which, as suggested previously, represent a homogeneous biochemical subtype.

\section{Summary}

A biochemical analysis of 82 Klebsiella strains is reported and some problems of nomenclature discussed. It is recommended that the name friedlaenderi be substituted for pneumoniae as the Klebsiella type species and further that type 3 strains be no longer designated rhinoscleroma. No evidence for any other valid species was found.

It is suggested that the distribution of various properties, including biochemical, in the Klebsiella genus be best described on a statistical rather than on an "all or none" basis. It is further emphasized that the results of any biochemical test must be qualified by reference to the particular technique employed. Biochemical aberrance is common in pneumoniae, especially type 1 strains. $K$. pneumoniae is much more heterogeneous than the type 3 species, of which only two subtypes, the aerogenic and anaerogenic, appear to exist. Typical pneumoniae strains are usually aerogenic, lactose, citrate, Voges-Proskauer, malonate, cyanide, gluconate, and lysine positive, and exhibit delayed hydrolysis of urea. Type 3 strains, apart from the rare anaerogenic variety, possess the reverse properties. Type 4-6 strains on the whole behave in an intermediate fashion. The value of the cyanide, gluconate, and lysine decarboxylase tests is stressed, and there is a high degree of correlation between them. The majority of all Klebsiella strains ferment adonitol and inositol, but not dulcitol, fail to produce indole and $\mathrm{H}_{2} \mathrm{~S}$, or to liquefy gelatin.

Attention is drawn to the sensitivity of anaerogenic type 3 strains to erythromycin, oleandomycin, and novobiocin. All other Klebsiellae are resistant to these antibiotics.

The author would like to thank Dr. I. Friedmann for his encouragement and Dr. S. T. Cowan for advice in this work, Drs. J. Taylor, P. H. Clarke, P. R. Edwards, and D. A. Osborn are also thanked for their help, Mr. D. Bawden for technical assistance, Mr. D. Connolly for photographs. and Messrs. Kemball, Bishop \& Co. Ltd., London, and Chas. Pfizer \& Co., New York, for their gifts of potassium gluconate.

\section{REFERENCES}

Braun, H. (1938). Schweiz. Z. allg. Path., 1, 257.

Breed, R. S., Murray, E. G. D., and Hitchens, A. Parker (1948). Bergey's Manual of Determinative Bacteriology, 6 th ed. Williams and Wilkins, Baltimore.

Christensen, W. B. (1946). J. Bact., 52, 461.

Clarke, P. H. (1953). J. gen. Microbiol., 8, 397. (1955). Ibid., 12, 337.

- and Tracey, M. V. (1956). Ibid., 14, 188.

Coppo, A. (1957). Antibiot. and Chemother., 7, 297.

Cowan, S. T. (1954). Int. Bull. bact. Nomencl., 4, 119.

- (1956). J. gen. Microbiol., 15, 235.

- (1957). Personal communication.

Difco Laboratories (1953). Difco Manual of Dehydrated Culture Media and Reagents for Microbiological and Clinical Laboratory Procedures, 9th ed., p. 173. Difco Laboratories, Detroit, Michigan.

Edwards, P. R. (1929). J. Bact., 17, 339.

- and Fife, M. A. (1955). Ibid., 70, 382. 
Epstein, S. S. (1959). J. Path. Bact. In press.

- and Friedmann, I. (1958). J. clin. Path., 11, 22. and Payne, P. (1959). J. Hyg. Camb. In press.

Erasmus, L. D. (1956). Quart. J. Med., 25, 507.

Finland, M., Murray, R., Harris, H. W., Kilham, L., and Meads, M. (1946). J. Amer. med. Ass., 132, 16.

Gale, E. F. (1946). Advanc. Enzymol., 6, 1.

Haynes, W. C. (1951). J. gen. Microbiol., 5, 939.

Henriksen, S. D. (1950). J. Bact., 60, 225.

(1952). Acta path. microbiol. scand., 30, 230.

(1954). Ibid., 34, 259.

Jennens, M. G. (1954). J. gen. Microbiol., 10, 121.

Kauffmann, F. (1949). Acta path. microbiol. scand., 26, 381.

(1954). Enterobacteriaceae, 2nd ed. Ejnar Munksgaard, Copenhagen.

Kligheer, I. J. (1914). J. infect. Dis., 15, 187.

Kohn, J. (1953a). J. clin. Path., 6, 243. (1953b). Ibid., 6, 249.
Koser, S. A. (1923). J. Bact., 8, 493.

Lautrop, H. (1956). Acta path. microbiol. scand., 39, 375.

Leifson, E. (1933). J. Bact., 26, 329.

Medical Research Council (1958). The National Collection of Type Cultures: Catalogue of Species. M.R.C. Memorandum No. 35.

Ministry of Health (1939). Bacteriological Examination of Water Supplies (rev. ed.). Reports on Public Health and Medical Subjects, No. 71.

Møller, V. (1954a). Acta path. microbiol. scand., 34, 102.

(1954b). Ibid., 34, 115.

- (1954c). Ibid., 35, 259.

(1955). Ibid., 36, 158.

Ørskov, I. (1952). Ibid., Suppl. 93, p. 259. (1957). Ibid., 40, 155.

Pickett, M. J., and Cabelli, V. J. (1953). J. gen. Microbiol., 9, 249.

Shaw, C., and Clarke, P. H. (1955). Ibid., 13, 155.

Sneath, P. H. A. (1957). Ibid., 17, 201.

Taylor, J. (1956). Personal communication.

Woiwod, A. J. (1949). J. gen. Microbiol., 3, 312. 